\title{
Let's get back to work: survival analysis on the return-to-work after depression
}

This article was published in the following Dove Press journal:

Neuropsychiatric Disease and Treatment

24 October 2013

Number of times this article has been viewed

\section{Pepijn Vemer' \\ Clazien A Bouwmans' \\ Moniek C Zijlstra-Vlasveld ${ }^{2}$ \\ Christina $M$ van der Feltz- \\ Cornelis ${ }^{2-4}$ \\ Leona Hakkaart-van Roijen' \\ 'Institute for Medical Technology Assessment, Erasmus University Rotterdam, Rotterdam, ${ }^{2}$ Institute of Mental Health and Addiction (Trimbos-institute), Utrecht, ${ }^{3}$ Tilburg University, Tranzo, Academic Centre 'Geestdrift', Tilburg, ${ }^{4}$ Clinical Centre for Body, Mind and Health, Tilburg, The Netherlands}

\section{Video abstract}

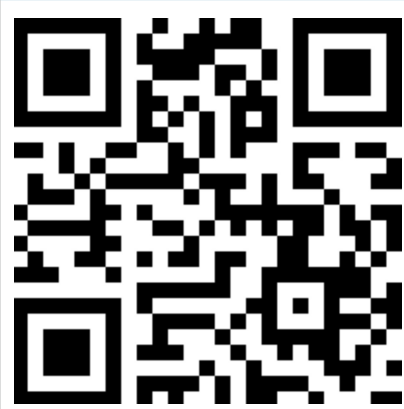

Point your SmartPhone at the code above. If you have a QR code reader the video abstract will appear. Or use: http://dvpr.es//955IIU

Correspondence: Pepijn Vemer Institute for Medical Technology Assessment, Erasmus University Rotterdam, PO Box 1738, 3000 DR, Rotterdam, The Netherlands

Tel +3I 104088564

Fax +31 10408 908I

Email pepijnvemer@gmail.com
Purpose: Absence from work due to mental disorders is substantial. Additionally, long-term absence from work is associated with a reduced probability of return-to-work (RTW). Major depressive disorder (MDD) is a prevalent condition in Dutch occupational health care settings. An early estimate of the prognosis regarding RTW in patients with MDD could serve both as a point of departure for the identification of high-risk cases and as an instrument to monitor the course of the disorder and of RTW. In the current study, we aimed to assess the added value of health-related quality of life (HRQoL) and severity of depression to predict the time to RTW. Patients and methods: Data were derived from a prospective longitudinal study aimed to evaluate the cost effectiveness of a collaborative care treatment in sick-listed workers with MDD. We included demographic, job-related, and health-related variables. Severity of depression was measured using the Patient Health Questionnaire Depression Scale-9 (PHQ-9). HRQoL was measured using two generic preference-based instruments, the EuroQol 5-Dimension (EQ-5D ${ }^{\mathrm{TM}}$ ) and the Medical Outcomes Study Short Form Health Survey (SF-36). A survival model was constructed by applying different survival functions to assess the best fit for the data. Additionally, survival analyses were performed to assess the added value of the two HRQoL measures and depression severity for predicting RTW.

Results: Females and older patients had a longer time to RTW. The same was true for patients with a full-time job and patients with more decision latitude. Patients in a management position and patients with more social support had a shorter time to RTW. Severity of depression was not predictive for the time to RTW. HRQoL measured by the SF-36 was a significant predictor for the time to RTW.

Conclusion: HRQoL emerged as a significant predictor for the time to RTW. However, severity of depression was not predictive for the time to RTW. These results suggest the importance of assessing HRQoL in addition to severity of disease to assess functionality.

Keywords: major depressive disorder, survival analyses, return-to-work, HRQoL

\section{Introduction}

The number of workers absent from work due to mental disorders such as depression is substantial in The Netherlands and in other Western countries. ${ }^{1-4}$ In a recent survey among workers in The Netherlands, the 1-year prevalence of depressive disorders was estimated at $4.2 \% .^{5}$ A study performed in the USA reported an average of 27.2 additional days of lost productivity due to absence from work or reduced work efficiency per year of workers with a depressive disorder. ${ }^{6}$ Based on data from The Netherlands Mental Health Survey and Incidence Study-2 (NEMESIS-2) it was estimated that workers with a depressive disorder have an average of 22.8 additional days of absence from work per year. ${ }^{5}$ However, Flach et $\mathrm{al}^{7}$ found sick leave durations of more than 
6 weeks in $62 \%$ of workers who were sick listed due to depressive disorder in The Netherlands. Apart from the individual suffering of mental health problems, associated sick leave has several other negative consequences. Long-term absence from work is associated with a reduced probability of returnto-work (RTW), which leads to a weakened financial position, social isolation, reduced quality of life, and exclusion from the labor market. ${ }^{8}$

Apart from these individual disadvantages, absence from work leads to an economic burden to society. ${ }^{9,10}$ An early estimate of the prognosis regarding RTW in patients with major depressive disorder (MDD) could serve both as a point of departure for the identification of high-risk cases and as an instrument to monitor the course of the disorder and of RTW.

In The Netherlands, the Gatekeeper Improvement Act requires employees at risk for long-term sickness absence to have contact with an occupational physician (OP) within 6 weeks of absence from work. Consequently, the OPs have opportunities for treatment and prevention. The identification of prognostic factors for patients at risk for long-term absence from work may facilitate the selection of patients who will most likely benefit from early interventions. Two recent systematic reviews of factors predicting RTW for people with poor mental health found that the factors ranged widely. For instance, factors were related to work (eg, job stress, threat of unemployment), health risk behaviors (eg, weight, smoking, drug dependence), social status (eg, marital status, sex, education), and medical condition (eg, severity of symptoms). However, the authors also concluded that the definitions of poor mental health varied widely, that studies had sometimes produced opposing results, and that further research is needed. ${ }^{11,12}$

In a recent study, severity of depression was found to be an important independent predictive factor for more days of absence from work. ${ }^{13}$

Health-related quality of life (HRQoL) is a common outcome measure in economic evaluations. Two studies investigated how HRQoL influenced RTW in patients with somatic diseases. Elfving et $\mathrm{al}^{14}$ found that bodily pain and social functioning, measured as domains within the Medical Outcomes Study Short Form Health Survey (SF-36), ${ }^{15}$ were predictive of increased working time after a multidisciplinary rehabilitation program among long-term sickness absentees with spinal pain.

Clay et $\mathrm{al}^{16}$ found significant associations between high social functioning (as a domain in the SF-36) and strong social relationships and earlier RTW following acute unintentional injuries.
No studies were found in which the prognostic value of preference-based HRQoL outcomes was evaluated in patients with mental disorders.

Hence, in the current study, we aimed to assess the added value of HRQoL and severity of depression alongside other factors to predict the time to RTW for workers listed as sick for at least 4 weeks due to MDD.

A priori, our hypotheses would be that a higher severity of depression and a lower HRQoL would lead to a longer time to RTW.

\section{Material and methods Study sample}

Data were derived from a prospective, longitudinal study, performed as part of The Netherlands Depression Initiative ${ }^{17,18}$ aimed to evaluate the cost effectiveness of a collaborative care treatment in sick-listed workers with MDD. ${ }^{19-21}$

The study was approved by the Medical Ethical Committee of the VU University Medical Centre, Amsterdam, The Netherlands. Recruitment was conducted in collaboration with a large Dutch occupational health service. Workers on sickness absence between 4 and 12 weeks were sent a questionnaire accompanied by written information about the study and an informed consent form. Respondents were screened on MDD using the Patient Health Questionnaire Depression Scale (PHQ-9, see below). Respondents who reached a cutoff score of 10 (moderate to severe MDD) on the PHQ-9 were contacted to arrange an appointment for the administration of the Mini-International Neuropsychiatric Interview (MINI) to assess whether the respondent met the Diagnostic and Statistical Manual of Mental Disorders, fourth edition (DSM-IV) criteria for MDD. ${ }^{22,23}$ Respondents were included if DSM-IV criteria for MDD were met and informed consent was given. Respondents with suicidal or psychotic symptoms or with a primary diagnosis of substance abuse or dependence, as assessed with the MINI interview, were excluded. A total of 126 workers were eligible for the study, of whom 122 were still on sick leave at the time of baseline measurement. Of these, 59 received care as usual and 63 were treated with the collaborative care treatment. At baseline, these workers had been on sick leave for an average of 70 days. The dependent variable in this study is the duration until full RTW, derived from the Occupational Health Service registration, starting from the moment of baseline measurement. Full RTW was defined as the first full RTW with equal earnings, lasting for at least 4 weeks. In accordance with the Dutch Health Law, two sickness absence episodes with less than 4 weeks of full RTW in between were counted as a single absence episode. 
Data were censored for workers whose sickness absence ended because they resigned from their job during the study $(n=15)$, and for workers who were still on sick leave at the end of the study $(n=14)$.

Baseline measurements included personal, job-related, and health-related data, including HRQoL measurements. Consequently, all data refer to the period before RTW.

\section{Demographic measures}

The personal information collected included demographic variables such as age, sex, living condition (ie, living alone, with an adult partner, with children, with parents), and education.

\section{Job-related measures}

Job-related information was measured with five scales from the Job Content Questionnaire (JCQ). ${ }^{24}$ The JCQ is a self-administered instrument that measures social and psychological characteristics of jobs. The aspects measured are decision latitude (nine items), including the dimensions skill discretion and decision authority; psychological job demands (five items); physical job demands (five items), including physical exertion and physical isometric loads; social support (eight items), including co-worker and supervisor support; and job insecurity (three items).

Additionally, respondents were asked whether their job comprised a management function and the total number of working hours and days per week at the start of sick leave.

\section{Health-related measures}

Health-related information included severity of depressive symptoms and somatization using the PHQ. ${ }^{25,26}$ The PHQ is a brief and reliable instrument that can be used to detect disorders in primary care. The depression scale of the PHQ, called the PHQ-9, ranges from 0 to 27. The somatization scale of the PHQ-15 ranges from 0 to 30. A higher score indicates a higher level of health problems. Additionally, self-reported co-morbid chronic disorders during the last 12 months were measured using a list derived from the Health Interview Survey of Statistics Netherlands (CBS) that contains 28 medical conditions. ${ }^{27}$ For each patient, the total number of chronic illnesses they had was recorded. In this study, data were derived from patients participating in a randomized controlled trial to evaluate the effectiveness of collaborative care in comparison with usual care. In the case of comparable effectiveness of alternative interventions, as was the case in this study, treatment groups may be combined. ${ }^{28}$ However, the PHQ-9 score was the outcome used in the effectiveness study. As the treatment may have impacted on the relationship between predictors and RTW, assignment to the alternative treatment interventions was added to the analyses as a covariate.

HRQoL was measured by two commonly applied generic preference-based measures, the EuroQol five-dimension $(\mathrm{EQ}-5 \mathrm{D})^{29}$ and the Short Form-36 (SF-36). ${ }^{15}$ The EQ-5D is a validated instrument for measuring general HRQoL covering five dimensions of health, ie, mobility, self-care, usual activities, pain/discomfort, and anxiety/depression. Each dimension is rated on a three-point scale with categories 'no problems', 'some problems', or 'extreme problems', resulting in a descriptive health profile. Respondents' health profiles were valued using valuations derived from the general population in The Netherlands. ${ }^{30}$

The SF-36 consists of 36 questions, yielding an eightscale profile of health: general health, physical functioning, role limitations (role-physical and role-emotional), social functioning, bodily pain, vitality, and mental health. A preference-based index score, known as the SF-6D (Medical Outcomes Study Short Form-6 dimensions), was calculated using 11 items of the SF-36 and valuations from the general UK population. ${ }^{31}$

\section{Survival analysis}

In this post hoc analysis, our aim was to calculate a survival model that would predict the number of days a sick worker would 'survive' in sick leave. We started with the definition of a survival model without covariates (Empty Model). We tested whether an exponential, Weibull, Gompertz, lognormal, log-logistic, or generalized gamma survival function would provide the best fit for our data. In this study, model fit was measured using Akaike's Information Criterion (AIC), Schwarz's Bayesian Information Criterion (BIC), and the Log-likelihood. In the case of nested models, we performed a likelihood ratio test. Based on these results, we selected the optimal functional form and added covariates using the forward selection procedure. Every time a new variable was added, we tested whether variables that were included earlier could be discarded without change in the estimated median survival. This change was assessed using the absolute value of the difference in median survival between a model with, and a model without the variable. We considered a change in survival significant if the average change over all patients was more than 2 weeks. Groups of variables that were closely linked (eg, the different aspects of the JCQ) were added at the same time and then evaluated individually. Variables were always tested in different forms, for example, as a logarithm, as a dummy variable, or as a categorical variable. After the 
researchers were satisfied with the fit of the model, we tested whether the chosen survival curve still had the best fit, or whether, including the covariates, a different survival curve would fit better. The resulting model was called the Full Model. Using this Full Model, we tested whether a measure of severity of MDD (the PHQ-9) or HRQoL (EQ-5D utility score and SF-6D utility index score) would provide added value when predicting RTW. We then performed an extra forward selection procedure to see whether variables that were discounted at an earlier stage were useful additions to the models including one of these three variables. The analyses were corrected for the duration of absence from work at entry into the study by adding this to the model as a covariate. The survival analyses were performed using Stata 12.0 (Statacorp, College Station, TX, USA).

\section{Results}

A total of 122 patients were included, with a RTW ranging from approximately 1 week to 143 weeks (average 34 weeks). Median RTW for uncensored observations was 20.9 weeks. Characteristics of the study population are presented in Table 1. Approximately 55\% were female; the average age was 43.4 years (standard deviation [SD] 11.1). Two patients were aged above the Dutch pension age of 65 years. Female patients were on average 4 years younger than male (not shown). The patients in the population worked on average 35 hours per week before their sick leave started. Almost $60 \%$ of the patients (71) worked full-time (36 hours per week or more). Generally, female workers had fewer working hours than their male counterparts (31 and 38 hours per week, respectively), which is in line with the Dutch working population. A management position was held by $22 \%$ of patients. At baseline, the average PHQ-9 score was 16 , which is classified as moderate severe MDD. ${ }^{25}$ The period between screening and inclusion into the study was, on average, 23 days. At baseline, the average utility score for the EQ-5D and the SF-6D was 0.582 (SD 0.238) and 0.565 (SD 0.064), respectively.

Multicollinearity was assessed using a correlation matrix of all parameters. Of the available variables, only several within the JCQ showed a correlation larger than 0.5 . This correlation was taken into account when assessing which combination of these parameters could be included in the Full Model due to multicollinearity. The three parameters of interest, PHQ-9, EQ-5D, and SF-6D, were also correlated, as would be expected.

Based on the AIC and BIC for the Empty Model, a log-normal survival function was preferred over the other calculated survival functions (see Table 2).
Table I Characteristics of the study population at baseline $(\mathrm{n}=122)$

\begin{tabular}{|c|c|}
\hline Sick leave in days: mean (range) & $70(35-155)$ \\
\hline \multicolumn{2}{|l|}{ Personal variables } \\
\hline Female (\%) & 54 \\
\hline Age: mean (range) & $43.5(21.5-7 \mid .3)$ \\
\hline \multicolumn{2}{|l|}{ Educational level (\%) } \\
\hline Low & 18.9 \\
\hline Moderate & 44.3 \\
\hline High & 35.3 \\
\hline Unknown & 1.6 \\
\hline \multicolumn{2}{|l|}{ Job-related variables } \\
\hline Working hours per week: mean (range) & $33.8(12-45)$ \\
\hline Working days per week: mean (range) & $4.5(2-5)$ \\
\hline Holds a management position (\%) & 22 \\
\hline JCQ - skill discretion: mean (range) & $34.6(14-48)$ \\
\hline JCQ - decision authority: mean (range) & $31.5(12-48)$ \\
\hline JCQ - psychological job demands: mean (range) & $35.1(19-46)$ \\
\hline JCQ - physical exertion: mean (range) & $6.1(3-12)$ \\
\hline JCQ - posture/physical isometric loads: mean (range) & $4.2(2-8)$ \\
\hline JCQ - job insecurity: mean (range) & $7.9(5-11)$ \\
\hline JCQ - supervisor support: mean (range) & $9.5(4-14)$ \\
\hline JCQ - co-worker support: mean (range) & $11.6(5-16)$ \\
\hline \multicolumn{2}{|l|}{ Health-related variables } \\
\hline \multicolumn{2}{|l|}{ Comorbidity (\%) } \\
\hline Hypertension & 20.5 \\
\hline Inflammation of head cavities & 13.1 \\
\hline Serious spinal affliction & 11.5 \\
\hline Migraine & 10.7 \\
\hline PHQ-9: mean (range) & $16.0(0-27)$ \\
\hline PHQ-I5: mean (range) & I3.I (0-27) \\
\hline \multirow[t]{2}{*}{ EQ-5D: mean (range) } & 0.582 \\
\hline & $(-0.058$ to 1.000$)$ \\
\hline \multirow[t]{2}{*}{ SF-6D: mean (range) } & 0.565 \\
\hline & $(0.38 I-0.746)$ \\
\hline Number of chronic illnesses: mean (range) & $1.3(0-6)$ \\
\hline
\end{tabular}

Notes: The educational levels 'low' and 'moderate' refer to different levels of general secondary education or pre-vocational secondary education. The educational level 'high' refers to higher professional or academic education. Skill discretion + decision authority = decision latitude; physical exertion + physical isometric loads = physical job demands; supervisor support + co-workers support $=$ social support. Abbreviations: EQ-5D, EuroQol 5-Dimension; JCQ, Job Content Questionnaire; PHQ-9, Patient Health Questionnaire Depression Scale-9; SF-6D, Medical Outcomes Study Short Form-6 dimensions.

Based on the log-likelihood, the generalized gamma function would be preferable, but a likelihood ratio test found no statistically significant differences between the log-normal and the generalized gamma functions $(P=0.45)$. We therefore continued with a log-normal survival function. The resulting models are presented in Table 3.

The Full Model comprises personal, job-related, and physical health-related variables. A total number of 116 observations, for which complete data were available, were used. The type of intervention that patients received was not predictive for the time to RTW. Female patients and older patients had a longer time to RTW than male patients and younger patients. Patients with a partner and no children 
Table 2 Estimation results for several survival curves, no covariates

\begin{tabular}{llll}
\hline & AIC & BIC & Log-likelihood (df) \\
\hline Exponential & 330.83 & 333.64 & $-164.42(\mathrm{I})$ \\
Weibull & 330.38 & 335.99 & $-163.19(2)$ \\
Gompertz & 332.67 & 338.28 & $-164.34(2)$ \\
Log-normal & 325.39 & 331.00 & $-160.69(2)$ \\
Log-logistic & 326.06 & 331.66 & $-161.03(2)$ \\
Generalized gamma & 326.83 & 335.24 & $-160.42(3)$ \\
\hline
\end{tabular}

Abbreviations: AIC, Akaike's Information Criterion; BIC, Bayesian Information Criterion; $d f$, degrees of freedom used in the likelihood ratio tests.

had an increased time to RTW in comparison to patients with other living conditions. Marital status and educational level were not found to be predictive of the time to RTW. Patients in a management position predicted a shorter time to RTW. A full-time job was a predictor of a longer time to RTW. The same was true for patients who had more decision latitude. Social support, from both their supervisor and their coworkers, resulted in less time to RTW. Other job-related variables, including other JCQ variables, were not found to be predictive for the time to RTW. Health-related variables, in the form of somatic comorbidities and the PHQ-15 scores, were not found to be significantly predictive for the time to RTW.

Adding depression severity (PHQ-9 Model) to the Full model did not improve the model fit, as seen by a higher $\mathrm{AIC}$ and BIC. The parameter was positive, meaning that more severely depressed patients had a longer time to RTW, but this association was not significant at a $10 \%$ level. The present formulation, using the PHQ-9 directly, had the lowest AIC and BIC. Other formulations that were tested were the natural logarithm of the PHQ-9, the PHQ-9 divided in five classes, and as an indicator variable for moderate to severe depression (PHQ-9 $\geq 10$ ). As expected from the small influence of this variable on the total RTW, the covariates were not changed compared with the Full Model.

Adding the SF-6D as a measure of HRQoL (SF-6D Model) significantly improved our model fit. The final formulation used was the logarithm of 1 minus the SF-6D, meaning that the positive parameter value indicates that patients with a higher HRQoL had a shorter time to RTW. This is in line with our a priori hypothesis about the association between HRQoL and the time to RTW. Adding EQ-5D as a measure of the HRQoL to the Full Model (EQ-5D Model) slightly improved model fit, although the parameter itself was not significant at a $10 \%$ level. The best formulation for the EQ-5D was a logarithm. In Figure 1, survival curves based on the SF-6D Model are presented. The graph shows the percentage of patients (vertical axis) that would still 'survive' on sick leave after a number of weeks (horizontal axis). All covariates were taken at the average for the entire population used to estimate the survival curve. The three curves show the difference for a patient with a low (SF-6D $=0.381)$, average $(0.570)$, and high (0.746) HRQoL. It clearly shows that a lower HRQoL leads

Table 3 Estimation results for return-to-work after depression, using log-normal survival models

\begin{tabular}{|c|c|c|c|c|}
\hline & Full Model & PHQ-9 Model & EQ-5D Model & SF-6D Model \\
\hline \multicolumn{5}{|l|}{ Personal variables } \\
\hline Female & $0.868 * * *$ & $0.886 * * *$ & $0.852 * * *$ & $0.716 * * *$ \\
\hline Age (in years) & $0.028 * * *$ & $0.029 * * *$ & $0.030 * * *$ & $0.022 * *$ \\
\hline Living with adult partner, no children & $0.433^{* *}$ & $0.434 * *$ & $0.438 * *$ & $0.330 *$ \\
\hline \multicolumn{5}{|l|}{ Job-related variables } \\
\hline Holds a management function & $-0.635^{* * *}$ & $-0.616 * * *$ & $-0.642 * * *$ & $-0.643 * * *$ \\
\hline Work week $\geq 36$ hours & $0.686^{* * *}$ & $0.712 * * *$ & $0.678 * * *$ & $0.64 I * * *$ \\
\hline Amount of decision latitude (JCQ) & $0.018^{* *}$ & $0.018 * *$ & $0.019 * *$ & 0.013 \\
\hline Amount of social support (JCQ) & $-0.075^{* *}$ & $-0.073^{* *}$ & $-0.063 * *$ & $-0.074 * * *$ \\
\hline Intervention (collaborative care) & -0.098 & -0.084 & -0.067 & -0.255 \\
\hline \multicolumn{5}{|l|}{ Health-related variables } \\
\hline PHQ-9 at baseline & & 0.017 & & \\
\hline EQ-5D at baseline $(\mathrm{In})$ & & & -0.210 & \\
\hline SF-6D at baseline $(\operatorname{In})^{\mathrm{a}}$ & & & & $1.167 *$ \\
\hline Constant & $1.728 * *$ & 1.281 & 1.180 & $3.540 * * *$ \\
\hline Sigma (ln) & -0.117 & -0.123 & -0.126 & $-0.148^{*}$ \\
\hline Number of observations & 116 & 116 & 114 & 99 \\
\hline Akaike's Information Criterion (AIC) & 288.3 & 289.4 & 284.1 & 246.4 \\
\hline Bayesian Information Criterion (BIC) & 315.9 & 319.7 & 314.2 & 274.9 \\
\hline
\end{tabular}

Notes: a Measured using the logarithm of I minus the SF-6D. *P<0.I; **P $<0.05$; ***P $<0.01$.

Abbreviations: EQ-5D, EuroQol 5-Dimension; JCQ, Job Contents Questionnaire; In, natural logarithm; PHQ-9, Patient Health Questionnaire Depression Scale-9; SF-6D, Medical Outcomes Study Short Form-6 dimensions. 


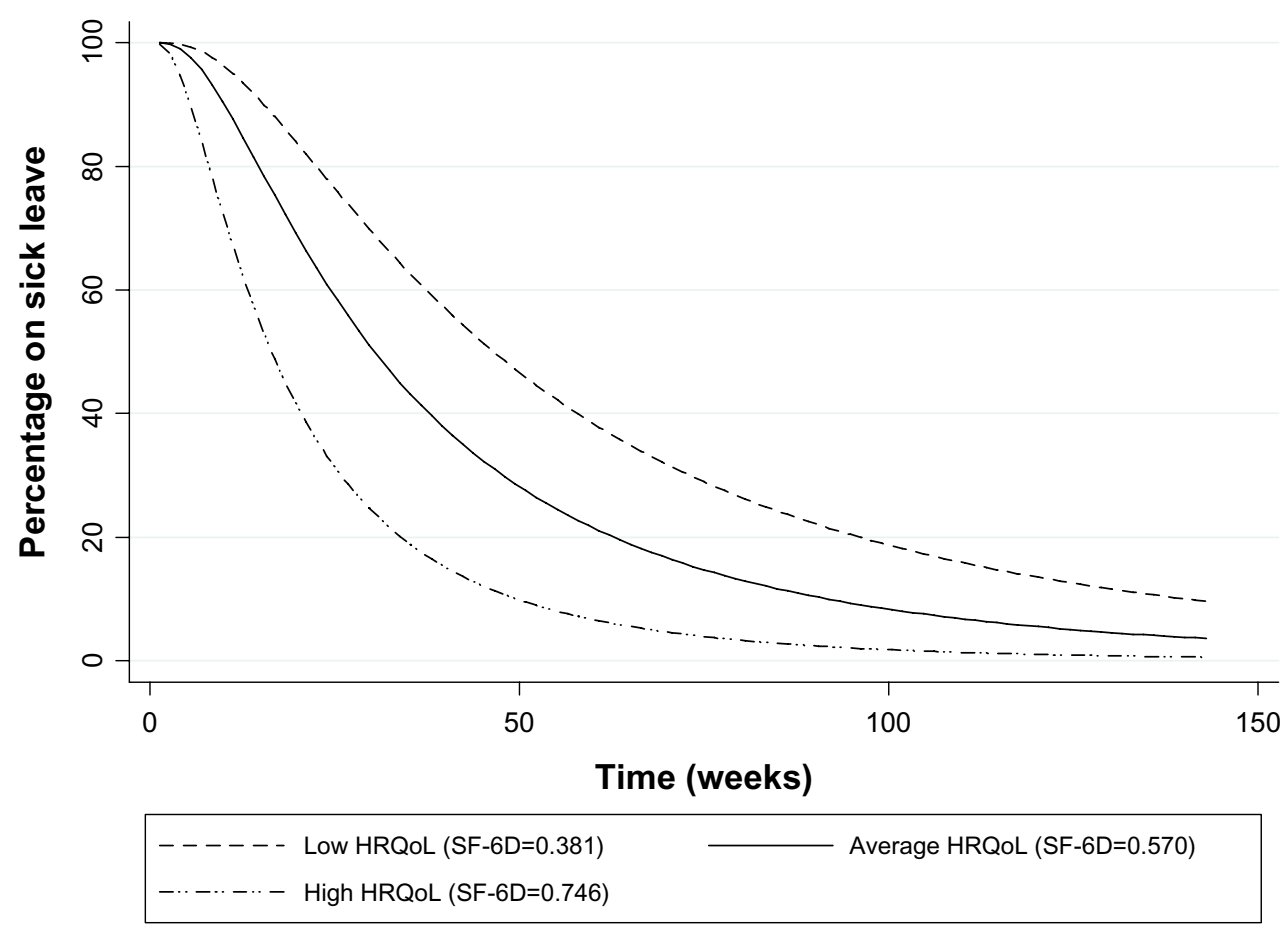

Figure I Estimated return-to-work for a patient with low, average, and high HRQoL, using the SF-6D model. Abbreviations: HRQoL, health-related quality of life; SF-6D, Medical Outcomes Study Short Form-6 dimensions.

to a longer time until RTW. The median time until RTW for a patient with average HRQoL is approximately 30 weeks, for a patient with low HRQoL almost 50 weeks, and for a patient with high HRQoL approximately 15 weeks.

\section{Discussion}

In this study, we have shown that HRQoL measures emerged as predictors of the time to RTW: workers with a worse HRQoL needed more time to RTW than those with a better HRQoL. This relationship was statistically significant using the SF-6D. Using the EQ-5D as a measure of HRQoL did lead to a better model fit, but the estimated coefficient was not significant at a $10 \%$ level. As opposed to what has been found previously ${ }^{13}$ severity of depression was not a predictor of the time to RTW.

The better fit of the EQ-5D Model and SF-6D Model was expressed in a lower AIC and BIC. However, it was also apparent that these models were calculated on fewer observations than the Full Model. For two observations, no EQ-5D value was available and 17 observations were missing for the SF-6D. To test the influence of these missing observations on our model, we calculated the Full Model, the EQ-5D Model, and the SF-6D Model on the 99 observations that had all necessary information. We concluded that adding the EQ-5D leads to an increase in AIC and BIC (and thus worsening of fit), instead of a decrease as seen previously. Adding the SF-6D to the Full Model still leads to an improvement of model fit. From this, we may conclude that the predictive value of the preference scores based on the EQ-5D may be even less strong than our primary results seem to suggest. The different predictive values of the EQ-5D and SF-6D scores may be explained by the different classification systems and the different dimensions of these instruments. Grieve et $\mathrm{al}^{32}$ indicated that the inclusion of items for vitality and social functioning of the SF-6D may partly explain the difference between the EQ-5D and the SF-6D.

However, more research, with different and especially more data, is necessary to corroborate these findings.

We have tested several covariates in the model that were found not to be predictive for the time to RTW. Educational level did not have any predictive value for the time to RTW. Neither the PHQ-15 scores nor the self-reported physical comorbidity were significantly predictive of the time to RTW. Nielsen et $\mathrm{al}^{33}$ found no significant association between sex, education, or cohabitation and the time to RTW in employees with mental health problems. A systematic review in patients suffering from poor mental health by Blank et al ${ }^{11}$ showed that a wide range of factors predict RTW and opposing results were found for older age and sex in predicting RTW. However, in the review by Cornelius et al ${ }^{12}$ strong evidence 
was found that older age was associated with time to RTW, and limited evidence was reported for other demographic, health-, or job-related factors in workers with mental disorders. Lagerveld et $\mathrm{al}^{2}$ conducted a review and found inconclusive evidence for demographic factors (eg, sex, age, education, and marital status), and moderate evidence for the presence of comorbid mental or physical disorders, severity of depressive disorder, and age being associated with duration of absence from work in depressed workers. As opposed to what was found earlier, ${ }^{13}$ severity of depressive symptoms, as measured by the PHQ-9, was not predictive for the time to RTW in our study. This is somewhat surprising, as severity of depression generally correlates with other outcomes. However, it was also shown that patients with clinically significant symptom improvement still exhibited persistent impairment in functioning. ${ }^{8}$

However, the comparison with other studies is hampered due to the use of different instruments to assess severity of depression and variations in methodological designs and stuvdy populations.

For the patients in our study, the duration of sick leave before baseline measurement ranged from 35 to 155 days, with an average of 70 days. The influence of differences in these sick leave episodes was examined using the days of sick leave before baseline measurement as a covariate in the full model. We did not find a significant influence of this on predicting time to RTW. Vlasveld et $\mathrm{al}^{34}$ examined associations of factors and RTW in workers on sickness absence due to all causes of illness. Significant factors found in this study were high physical job demands, high physical symptoms, and older age. Additionally, Vlasveld et $\mathrm{al}^{34}$ found that moderate to severe depression was associated with a longer time to RTW. Differences with our findings can be attributable to four reasons. First, the study populations differ. In the current study, the study population consists of employees on sick leave due to MDD, while the study population of Vlasveld et $\mathrm{al}^{34}$ consisted of workers on sick leave due to any cause of illness. Second, Vlasveld et $a l^{34}$ used a Cox Proportional Hazard function, which does not require a parametric functional form for survival. The extra limitation of imposing a functional form as the log-normal in our study is necessary in order to calculate median survival. Further, Vlasveld et al ${ }^{34}$ only used covariates on a dichotomous scale. We tested all variables in different forms, which might influence the effect of the PHQ-9. Finally, the data in Vlasveld et $\mathrm{al}^{34}$ were censored after 1 year of observation. We only censored observations if absence ended due to resignation and if absence was not ended at the time of the study. Apart from throwing away valuable information, this may lead to bias in survival analysis.

Our study has several limitations. Any available information from the time before inclusion was limited to information based on occupational registrations. Lagerveld et $\mathrm{al}^{2}$ found strong evidence for an association between work disability and longer duration of depression.

However, we did not have information about the duration of MDD before the start of sick leave. Additionally, we did not have information about other variables that may contribute to the time to RTW, eg, psychiatric comorbidity, pharmacologic treatment of MDD, or previous depressive episodes. Other relevant factors that may contribute to RTW that were not included in this study are occupational factors such as the size of the enterprise and levels of occupational health staff, and individual factors such as health behaviors and family situations. More research is recommended to fully evaluate the relevant contributing factors of RTW. The findings in our study apply only to patients with moderate or severe depression, as patients with mild depression at the time of screening were not invited to participate in this study. Additionally, only patients who had already been on sick leave for at least 4 weeks were included. Although MDD is generally associated with relatively long episodes of sick leave, this may limit the generalizability of our findings to all patients with MDD. Additionally, the validity of the PHQ-9 as an instrument to measure depression severity is still under discussion. ${ }^{35}$ More research is recommended using alternative instruments to measure severity of MDD. Another limitation concerns the sample size of the study. The sample size limits the number of variables that can be taken into account. Applying larger sample sizes may result in additional significant predictors of RTW. Several studies report on the predictive value of depression on RTW in comparison with populations without a depressive disorder. ${ }^{33,34}$

To our knowledge, our study is the first to explore the influence of factors of severity of MDD and HRQoL on RTW in a population with MDD.

\section{Conclusion}

Our study showed that RTW was not significantly associated with severity of depression. However, HRQoL, measured with the SF-6D, was a significant predictor of the time to RTW. These results suggest the importance of assessing HRQoL in addition to severity of MDD to assess functionality. 


\section{Acknowledgment}

The study was supported financially by Laboratoire Lundbeck, France. This study used data that was collected in the Depression Initiative, funded by Innovatiefonds Zorgverzekeraars.

\section{Disclosure}

The authors report no conflicts of interest in this work.

\section{References}

1. Lerner D, Henke R. What does research tell us about depression, job performance, and work productivity? J Occup Environ Med. 2008;50(4): 401-410.

2. Lagerveld S, Bültmann U, Franche RL, et al. Factors associated with work participation and work functioning in depressed workers: a systematic review. J Occup Rehabil. 2010;20(3):275-292.

3. Henderson M, Glozier N, Holland Elliott K. Long term sickness absence. BMJ. 2005;330(7495):802-803.

4. Druss BG, Rosenheck RA, Sledge WH. Health and disability costs of depressive illness in a major US corporation. Am J Psychiatry. 2000;157(8):1274-1278.

5. de Graaf R, Tuithof M, van Dorsselaer S, ten Have M. Sick Leave due to Psychological and Somatic Disorders among Workers. Results of the 'Netherlands Mental Health Survey and Incidence Study-2' (NEMESIS-2). Utrecht: Netherlands Institute of Mental Health and Addiction; 2011. Dutch.

6. Kessler RC, Akiskal HS, Ames M, et al. Prevalence and effects of mood disorders on work performance in a nationally representative sample of US workers. Am J Psychiatry. 2006;163(9):1561-1568.

7. Flach PA, Groothoff JW, Krol B, Bültmann U. Factors associated with first return to work and sick leave durations in workers with common mental disorders. Eur J Public Health. 2012;22(3):440-445.

8. Dekkers-Sánchez PM, Hoving JL, Sluiter JK, Frings-Dresen MH. Factors associated with long-term sick leave in sick-listed employees: a systematic review. Occup Environ Med. 2008;65(3):153-157.

9. van Roijen LH, van Straten A, Al M, Rutten F, Donker M. Cost-utility of brief psychological treatment for depression and anxiety. $\mathrm{Br} J$ Psychiatry. 2006;188:323-329.

10. Krol M, Papenburg J, Koopmanschap M, Brouwer W. Do productivity costs matter? The impact of including productivity costs on the incremental costs of interventions targeted at depressive disorders. Pharmacoeconomics. 2011;29(7):601-619.

11. Blank L, Peters J, Pickvance S, Wilford J, Macdonald E. A systematic review of the factors which predict return to work for people suffering episodes of poor mental health. J Occup Rehabil. 2008;18(1): 27-34.

12. Cornelius LR, van der Klink JJ, Groothoff JW, Brouwer S. Prognostic factors of long term disability due to mental disorders: a systematic review. J Occup Rehabil. 2011;21(2):259-274.

13. Hees HL, Koeter MW, Schene AH. Predictors of long-term return to work and symptom remission in sick-listed patients with major depression. J Clin Psychiatry. 2012;73(8):e1048-e1055.

14. Elfving B, Asell M, Ropponen A, Alexanderson K. What factors predict full or partial return to work among sickness absentees with spinal pain participating in rehabilitation? Disabil Rehabil. 2009;31(16): 1318-1327.

15. Ware JE Jr, Sherbourne CD. The MOS 36-item short-form health survey (SF-36). I. Conceptual framework and item selection. Med Care. 1992;30(6):473-483.

16. Clay FJ, Fitzharris M, Kerr E, McClure RJ, Watson WL. The association of social functioning, social relationships and the receipt of compensation with time to return to work following unintentional injuries to Victorian workers. J Occup Rehabil. 2012;22(3):363-375.
17. de Jong FJ, van Steenbergen-Weijenburg KM, Huijbregts KM, et al. The depression initiative. Description of a collaborative care model for depression and of the factors influencing its implementation in the primary care setting in The Netherlands. Int J Integr Care. 2009;9:e81.

18. van der Feltz-Cornelis CM. Towards integrated primary health care for depressive disorder in The Netherlands. The depression initiative. Int $J$ Integr Care. 2009;9:e83.

19. Vlasveld MC, van der Feltz-Cornelis CM, Adèr HJ, et al. Collaborative care for major depressive disorder in an occupational healthcare setting. Br J Psychiatry. 2012;200(6):510-511.

20. Vlasveld MC, Anema JR, Beekman AT, et al. Multidisciplinary collaborative care for depressive disorder in the occupational health setting: design of a randomised controlled trial and cost-effectiveness study. BMC Health Serv Res. 2008;8:99.

21. Vlasveld MC, van der Feltz-Cornelis CM, Adèr HJ, et al. Collaborative care for sick-listed workers with major depressive disorder: a randomised controlled trial from The Netherlands Depression Initiative aimed at return to work and depressive symptoms. Occup Environ Med. 2013;70(4):223-230.

22. Sheehan DV, Lecrubier Y, Sheehan KH, et al. The Mini-International Neuropsychiatric Interview (MINI): the development and validation of a structured diagnostic psychiatric interview for DSM-IV and ICD-10. J Clin Psychiatry. 1998;59 Suppl 20:22-33.

23. Vliet vI, Beurs dE. [The MINI-International Neuropsychiatric Interview. A brief structured diagnostic psychiatric interview for DSM-IV en ICD-10 psychiatric disorders.] Tijdschr Psychiatr. 2007;49(6):393-397. Dutch.

24. Karasek R, Brisson C, Kawakami N, Houtman I, Bongers P, Amick B. The Job Content Questionnaire (JCQ): an instrument for internationally comparative assessments of psychosocial job characteristics. J Occ Health Psychol. 1998;3(4):322-355.

25. Kroenke K, Spitzer RL, Williams JB. The PHQ-9. Validity of a brief depression severity measure. J Gen Intern Med. 2001;16(9):606-613.

26. Kroenke K, Sptitzer RL, Williams JB. The PHQ-15: validity of a new measure for evaluating the severity of somatic symptoms. Psychosom Med. 2002;64(2):258-266.

27. Questionnaires Health Inquiry 2010 [webpage on the Internet]. Den Haag: Statistics Netherlands (CBS); 2010. Available from: http:// www.cbs.nl/nl-NL/menu/themas/gezondheid-welzijn/methoden/ dataverzameling/overige-dataverzameling/2011-ge2010-vragenlijsten. htm. Accessed August 16, 2012.

28. Moons KG, Royston P, Vergouwe Y, Grobbee DE, Altman DG. Prognosis and prognostic research: what, why, and how? $B M J$. 2009;338:b375.

29. Brooks R. EuroQol: The current state of play. Health Policy. 1996; 37(1):53-72.

30. Lamers LM, Stalmeier PF, McDonnell J, Krabbe PF, van Busschbach JJ. [Measuring the quality of life in economic evaluations: the Dutch EQ-5D tariff.] Ned Tijdschr Geneeskd. 2005;149(28):1574-1578. Dutch.

31. Brazier J, Roberts J, Deverill M. The estimation of a preferencebased measure of health from the SF-36. J Health Econ. 2002;21(2): 271-292.

32. Grieve R, Grishchenko M, Cairns J. SF-6D versus EQ-5D: reasons for differences in utility scores and impact on reported cost-utility. Eur J Health Econ. 2009;10(1):15-23.

33. Nielsen MB, Bültmann U, Madsen IE, et al. Health, work, and personalrelated predictors of time to return to work among employees with mental health problems. Disabil Rehabil. 2012;34(15):1311-1316.

34. Vlasveld MC, van der Feltz-Cornelis CM, Bültmann U, et al. Predicting return to work in workers with all-cause sickness absence greater than 4 weeks: a prospective cohort study. J Occup Rehabil. 2012;22(1):118-126.

35. Zimmerman M, Martinez JH, Friedman M, Boerescu DA, Attiullah N, Toba C. How can we use depression severity to guide treatment selection when measures of depression categorize patients differently? J Clin Psychiatry. 2012;73(10):1287-1291. 
Neuropsychiatric Disease and Treatment

Dovepress

\section{Publish your work in this journal}

Neuropsychiatric Disease and Treatment is an international, peerreviewed journal of clinical therapeutics and pharmacology focusing on concise rapid reporting of clinical or pre-clinical studies on a range of neuropsychiatric and neurological disorders. This journa is indexed on PubMed Central, the 'PsycINFO' database and CAS.

The manuscript management system is completely online and includes a very quick and fair peer-review system, which is all easy to use. Visit http://www.dovepress.com/testimonials.php to read real quotes from published authors.

Submit your manuscript here: http://www.dovepress.com/neuropsychiatric-disease-and-treatment-journal 